\title{
Validation of a new hot tearing criterion using the ring mould test
}

\author{
J.-M. Drezet
}

\author{
Laboratoire de Métallurgie Physique, École Polytechnique Fédérale de Lausanne, MX-G, \\ 1015 Lausanne, Switzerland
}

\begin{abstract}
Hot tear is one of the most serious defect which a casting can suffer. It represents a major limitation to the production of foundry cast parts and to the productivity of continuous casting processes such as the direct chill casting of aluminium alloys. As an exemple, the starting phase of the direct chill casting process remains particularly critical for some aluminium alloys because of their high propensity to develop either hot tears which initiate at non zero liquid fraction, or cold cracks which nucleate and grow exclusively in the solid metal. In order to validate a new hot tearing criterion recently proposed by Rappaz and Drezet [1], instrumented ring mould tests were carried out with aluminium alloys of different composition and further on analysed from a thermal, mechanical and microstructural point of view. The thermal field obtained in the test was determined with the help of an inverse method using five temperature histories measured at different locations and the stress build-up was computed with a transient thermomechanical model implemented in the finite element package Abaqus. Deformation in the solid was assumed to obey a viscoplastic law and the cooling conditions were those deduced by the inverse method. The new hot tearing criterion [1] based on the ability of the interdendritic flow of liquid to compensate for the thermally induced deformation of the roots of columnar dendrites, allowed the calculation of the maximum strain rate that the roots of the dendrites can undergo without initiation and/or propagation of hot tears. After implementation in the numerical FEM model of the ring mould test, the hot tearing criterion predicted the occurrence of tears precisely in the region where hot cracks were observed after the test. More generally, when implemented in thermomechanical models of casting processes, the present hot tearing criterion would be very helpful in diminishing the cracking tendency.
\end{abstract}

\section{INTRODUCTION}

Solidification cracks are a common and serious defect encountered in both ferrous and non-ferrous castings and welds. Many aluminium alloys are susceptible to the two general types of cracks: stress or cold cracks and solidification cracks, otherwise known as hot cracks or hot tears. The essential difference between these two types of cracks is that the former propagate below the non equilibrium solidus temperature, that is in a fully solid material, whereas the latter propagate above it. Hot tears are found to be interdendritic and often discontinuous in nature [2]. They are usually found at a hot spot, i.e. a sudden enlargement in the cross section of a casting or where the heat transfer is reduced locally in the mould. They can also be found near a re-entrant corner of a casting.

In casting, the hot cracking of metals has been studied using various devices. The idea is to create tensile stresses by constraining some parts of the casting. This can be done by using a bone-shape structure in which the ends solidify first [3]. The part which is in the middle solidifying later, it is under tensile stress along the bone direction and cracks form in the perpendicular direction. Using such a device, Clyne and Davies [4] have estimated the final density of cracks by measuring the electrical resistivity since the electrical current cannot flow through the cracks. They compared these values with crack densities measured by standard metallographic inspection. They defined the cracking susceptibility, $X_{\mathrm{cr}}$, in such a way that it is 0 for a completely uncracked specimen and 1 for a fully cracked section. Another way to measure crack sensitivity is to use a mould with an inner cylindrical core made out of a strong material. As the alloy starts to solidify around the core, it experiences hoop and axial thermally-induced stresses and depending on the conditions of casting, hot tears might develop near the inner tube. Warrington and McCartney [5] have recently designed a new test, known now as the cold finger test. The principle of the test is to solidify an alloy around a water cooled copper chill in the form of a cone. Providing a narrow vertical stripe of graphite is painted onto the surface of the cone prior to the immersion of the cone into the 
melt then only one open hot-tear forms in the ingot at the position of the stripe or hot-spot. Because of the tapered nature of the restraint, i.e. the copper chill, the distance the crack propagates down the side of the ingot give a direct measure of the hot-cracking susceptibility of a given alloy.

As mentioned by several authors and summarised by Rappaz [6], the zone of the mush which is most sensitive to hot-tearing appears to be where the film of interdendritic liquid is still continuous and no bridging of the dendrite arms has yet occurred while the permeability is low and the feeding of such zones is difficult. In this case, a tensile stress will have the tendency to pull apart the dendrite trunks or the dendritic grains and the liquid film will not resist. However, if the solid fraction is not too large, feeding of these open parts will allow to "heal" these hot-tears. On the other hand, at high solid fraction, feeding is no longer possible and hot tears will result. Minute solute elements which lower the temperature of the last solid to form can play a detrimental role in hot-cracking. As a first analysis, many authors considered that the hot-cracking tendency was simply a function of the extent of the mushy zone or of the solidification interval. Their criteria for cracking sensitivity were then based upon the shape of the $f_{S}(T)$ or $f_{s}(t)$ curve : the cruder ones take the whole solidification interval using the lever rule for a binary alloy; more refined approaches consider some back-diffusion in the solid [2].

As an alternative, Clyne and Davies introduced a Cracking Sensitivity Coefficient (CSC) which is given by the ratio of two times [4] :

$$
\mathrm{CSC}=\frac{\mathrm{t}_{\mathrm{V}}}{\mathrm{t}_{\mathrm{r}}}
$$

where $t_{v}$ is the time during which the mushy zone is vulnerable to hot tearing and $t_{\mathrm{r}}$ is the time during which stresses can be relaxed. These authors considered that the first time occurs for $0.01<f_{1}<0.1$, where $f_{1}$ $=\left(1-f_{\mathrm{S}}\right)$ is the fraction of liquid. Below the value of 0.01 , dendrite arms are supposed to have established bridges whereas for $f_{l}>0.1$, the permeability is supposed to be such that feeding can heal an opening of the mush. Clyne and Davies considered that the time for stress relaxation, $t_{r}$, occurs for $0.1<f_{1}<0.6$. On the other hand, Feurer [7] has proposed a theory to explain hot-tearing tendency from a concept which is definitely more relevant to microporosity formation. As a matter of fact, a clear distinction should be made between microporosity and hot-tears [6] : both result finally from a lack of feeding but the first defect is associated with the solidification shrinkage (hydrostatic depression) whereas, the second one is due to thermally-induced uniaxial tensile stresses as pointed out by Guven and Hunt [8]. These authors have shown that hot-tears form in the aluminium-copper system only if the casting is restrained from opposite solidifying zones, i.e. if a hot spot under tensile stress is created.

Hot cracking is difficult to model because it requires the knowledge of both the mechanical behaviour of the solid phase and the characteristics of the liquid flow in the interdendritic region. Although the mechanical behaviour of semi-solid alloys is of great importance for the modelling of thermomechanical stresses and hot tearing during casting, it is usually poorly known. The measurement of rheological properties in the semi-solid range was the aim of a few recent works [9-12].

A hot tearing model based on the interaction between the stress/strain development in the solid part in one hand and the ability of the liquid to compensate for this deformation on the other hand was recently derived for columnar microstructures by Rappaz and Drezet [1]. The goal of the present paper is to validate this hot tearing criterion through the ring mould test and the implementation of the proposed criterion in a FEM model of the test. Section 2 is dedicated to the presentation of the classic ring mould test aimed at studying the hot tearing susceptibility of a given alloy. In section 3, a thermomechanical model of the test is presented. The thermal boundary conditions were determined using the temperature histories measured at five points during casting and the stress/strain fields were computed using a viscoplastic description of the alloy. Section 4 is dedicated to the presentation of the new hot tearing criterion. Eventually, in section 5, the implementation of the criterion in the FEM model of the test will be presented and the predicted zone where hot tearing is most probable will be compared with the observed one.

\section{EXPERIMENTAL INVESTIGATION}

The set-up used for the ring mould test is schematically presented in figure 1. Liquid metal is poured into the open annulus between the inner and outer parts of the preheated mould. Then, as cooling water starts to circulate inside the inner tube, the metal cools down and contracts onto the inner steel core, $20 \mathrm{~mm}$ in diameter. The resulting constraint on the casting is severe, opening up tears all around the ring in a susceptible alloy. A non-grain refined $\mathrm{Al}-\mathrm{Cu} 4.5 \mathrm{wt}$ pct was used for the tests. After complete solidification and cooling of the part, horizontal and vertical sections were cut, polished and then etched in order to reveal 
the presence of cracks in the specimen. Two types of cracks were found as shown in figure 2: "axial tears" initiated by axial stresses can be seen in vertical sections of the ring whereas "hoop cracks" initiated by hoop stress are visible in horizontal sections. In order to determine the heat extracted by the cooling water through the inner tube, five K-type thermocouples were introduced in the mould before pouring. The thermal histories were measured at mid-height of the casting and at five different distances from the inner core as shown in figure 1 .

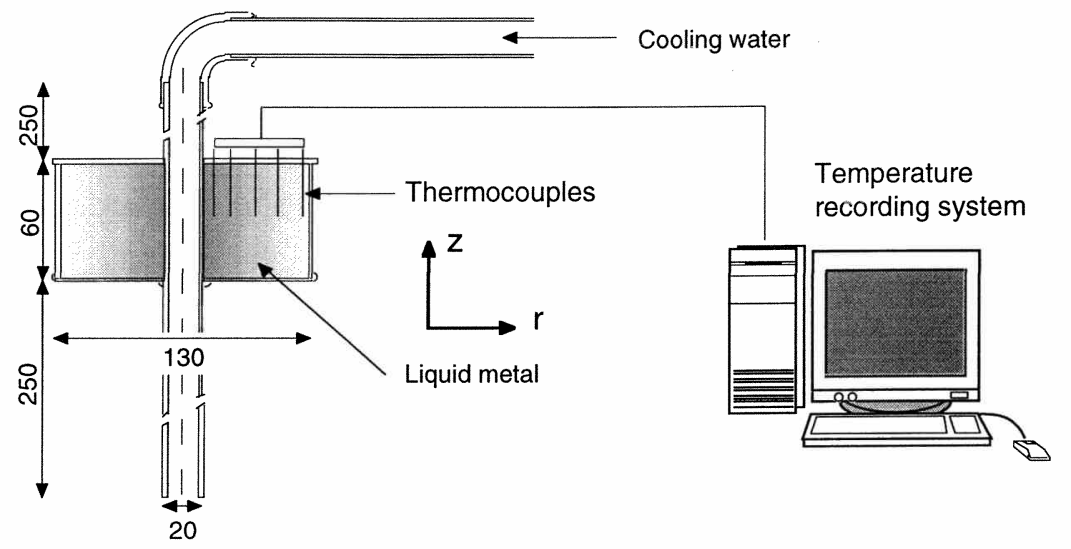

Figure 1: schematic view of the set-up used for the ring mould test (unit is $\mathrm{mm}$ ).
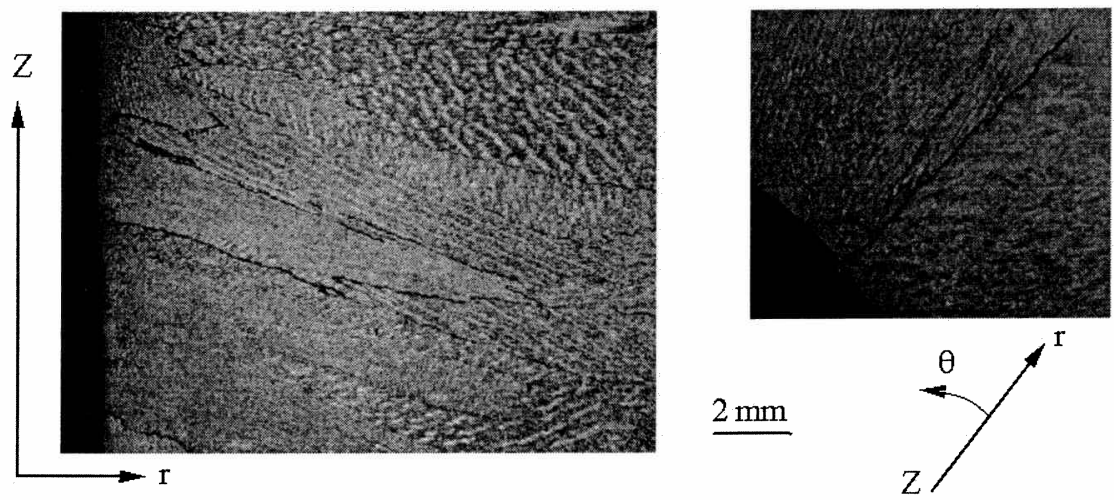

Figure 2: vertical (left) and horizontal (right) sections of the ring revealing the columnar structure and the presence of axial (left) and hoop tears (right) obtained with an $\mathrm{Al}-\mathrm{Cu} 4.5 \%$ alloy.

Figure 3 shows the fractograph of an axial crack obtained by scanning electron microscopy (SEM) using secondary electrons. This picture reveals the intergranular nature of the hot tearing phenomenon. One can also note the presence of microcracks around the macrocracks. These microcracks may have grown form localised intergranular porosity and further on lead to a pre-damaging of the solidifying material. During solidification, local thermal stresses were relaxed by the initiation and propagation of one macrocrack through the most favorably oriented grain boundaries. 


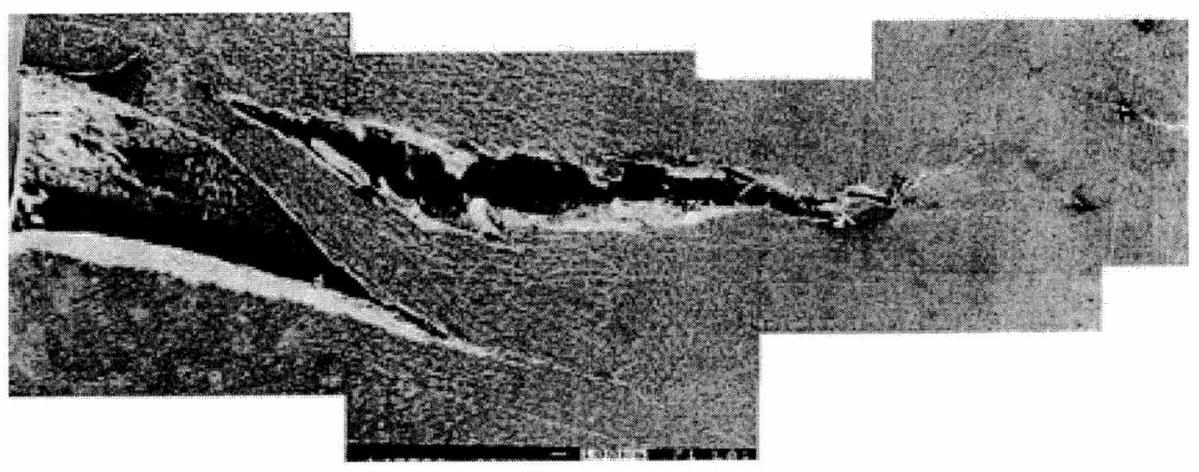

Figure 3: Scanning electron microscopy (SEM) fractograph of an axial macrocrack and the surrounding microcracks revealing the intergranular nature of the hot tearing.

\section{VISCOPLASTIC MODEL OF THE RING MOULD TEST}

Due to axisymmetric conditions, the thermal and stress/strain fields were computed in a vertical section of the casting. In a first step, the measured cooling curves were used to deduce by an inverse method the thermal boundary conditions which were applied in a second step in a thermomechanical model of the test.

\subsection{Determination of the thermal boundary conditions}

Assuming that the heat extraction on the upper surface, external and lower surface of the part are negligible compared to the cooling by the inner tube, adiabatic boundary conditions were specified on these surfaces. On the other hand, the thermal flux through the inner tube was assumed to obey a Cauchy-type law with a time dependent heat-transfer coefficient and a constant sink temperature of $15^{\circ} \mathrm{C}$. The principle of the inverse method is to determine this heat-transfer coefficient so that computed and measured cooling curves become as close as possible. More details of this method can be found in [13]. Using the code calcoMOS, it was found that after the cooling has started, the heat transfer coefficient increases rapidly from a value of $0.5 \mathrm{~kW} / \mathrm{m}^{2} \mathrm{~K}$ to reach a plateau at $2.5 \mathrm{~kW} / \mathrm{m}^{2} \mathrm{~K}$ up to the complete cooling of the specimen. Indeed, as solidification progresses, the alloy contracts on the inner tube and the heat transfer increases. This timedependent heat transfer coefficient was used in the subsequent thermomechanical computations.

\subsection{Thermomechanical model}

In order to predict the stress/strain development during the test, transient thermomechanical computations were carried out from the end of the pouring stage under the assumption that the thermal field is uniform, up to the complete cooling of the specimen at room temperature. The finite element program ABAQUS was employed to perform the numerical computations. The coupled heat transfer/stress analysis was performed using 4-nodes axisymmetric quadrilateral elements, bilinear in displacement and temperature. Assuming that the inner core was rigid, the points were free to move on the lower and upper faces of the 2D section whereas those in contact with the inner core were fixed owing to the contraction and the sticking of the metal on the inner tube. With the assumption of instantaneous mechanical equilibrium, the variation of the internal stress tensor was computed using an incremental deformation tensor, $\delta \underline{\varepsilon}$, made out of an elastic $\delta \underline{\varepsilon}_{\mathrm{e}}$, thermal $\delta \underline{\varepsilon}_{\mathrm{th}}$, and viscoplastic component, $\delta \underline{\varepsilon}_{\mathrm{vp}}[14,15]$ :

$$
\delta \underline{\varepsilon}=\delta \underline{\varepsilon}_{\mathrm{e}}+\delta \underline{\varepsilon}_{\mathrm{th}}+\delta \underline{\varepsilon}_{\mathrm{vp}}
$$

The elastic deformations were related to the internal stresses by Hooke's law $\delta \underline{\sigma}=[D] \cdot \delta \underline{\varepsilon}$, where $[D]$ is the stiffness matrix defined in terms of the Young and Poisson moduli, $\mathrm{E}$ and $v$. The thermal deformations 
were related to the local temperature variation, $\delta \mathrm{T}$, through the equation $\delta \varepsilon_{\mathrm{ij}}=\alpha \cdot \delta \mathrm{T} \cdot \delta_{\mathrm{ij}}$, where $\alpha$ is the linear expansion coefficient and $\delta_{\mathrm{ij}}$ is the Kronecker symbol. The thermal contraction of the alloy was taken into account as soon as the metal had reached its coherency temperature, $635^{\circ} \mathrm{C}$. A very low Young's modulus was affected to the liquid metal and fluid motion was neglected. As we were interested in the stress build up only in the early stages of cooling, the contribution of the metal shrinkage during solidification was neglected, owing to some liquid feeding within the mushy zone to compensate for the density variation [14].

The viscoplastic behaviour of the metal was taken into account in the model using a perfect plastic yield stress surface with no hardening effects and with a rate-dependent yield strength (so-called rate-dependent plasticity). This means that when the equivalent Von Mises stress is larger than the threshold stress $\sigma_{0}$, the viscoplastic strain rate is given by [15]:

$$
\dot{\varepsilon}_{\mathrm{vp}}=\left[\frac{\sigma_{\mathrm{vm}}-\sigma_{0}}{\mathrm{~K}}\right]^{1 / \mathrm{m}}
$$

The values of the threshold stress $\sigma_{0}$, the viscoplastic consistency $\mathrm{K}$ and the strain rate sensitivity, $\mathrm{m}$, at different temperatures were measured by Decultieux [3] for the $\mathrm{AlCu} 4.5 \% \mathrm{Mg} 0.3 \%$ alloy and used in the present study.

\subsection{Computed stress/strain field in the mush}

Figure 4 shows the computed radial $\left(\sigma_{\mathrm{rr}}\right)$, axial $\left(\sigma_{\mathrm{zZ}}\right)$, and hoop $\left(\sigma_{\theta \theta}\right)$ stress components, when the alloy has reached its eutectic temperature $\left(548^{\circ} \mathrm{C}\right)$ on the inner core. Also shown on this figure is the computed thermal profile in the part. The solidified part is in compression radially but remains in tension along the $\mathrm{zz}$ and $\theta \theta$ directions. The thermal contraction of the alloy on the central tube leads to some tensile stresses in the mushy zone at temperatures higher than the eutectic temperature where solidification finishes (root of the dendrites). According to the macrographs of figure 2, this high tension stress level near the central core was relaxed by the initiation of hot tears. Please note that significant stresses do not appear at the coherency temperature but at a lower temperature when the threshold stress $\sigma_{0}$ takes a positive value (cf. equation 3 ).

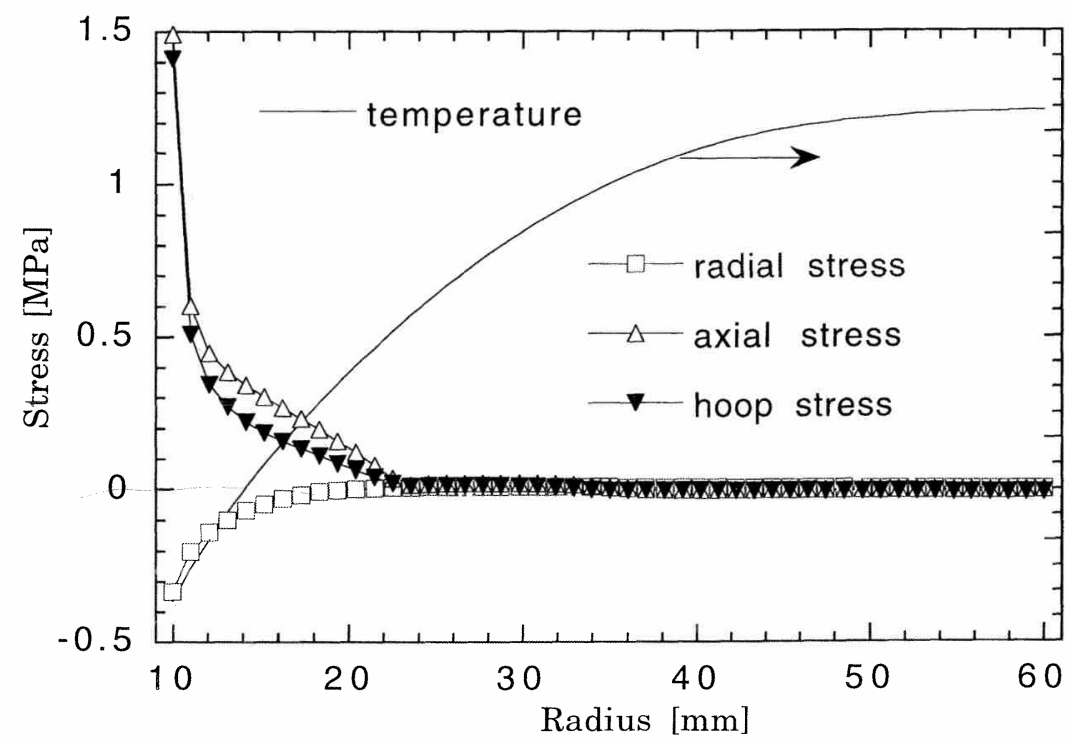

660

640

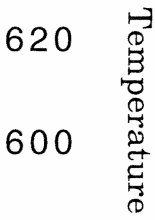

580 อ으

560

540

Figure 4: computed stress state and temperature profile when the alloy reaches its eutectic temperature $\left(548^{\circ} \mathrm{C}\right)$ on the inner tube $(\mathrm{r}=10 \mathrm{~mm})$. 


\section{HOT TEARING IN COLUMNAR MICROSTRUCTURE}

\subsection{Critical region of the mushy zone}

In order to illustrate the problem of hot cracking formation, the aspect of a mushy zone of a succinonitrileacetone organic alloy is shown in Figure 5. This alloy was directionally solidified between two glass plates using a Bridgman-type experiment and the formation of the dendrites was observed by transmission light microscopy at various stages. The time indicated below each figure has been calculated from the dendrite tip position using the constant solidification rate or speed of the isotherms v. For each figure, the volume fraction of solid, fs, has been estimated by visual inspection. Various stages can be distinguished. In Figure 5a, the dendritic network is very open and the interdendritic liquid can flow without difficulties (this is the region of importance for convection-induced macrosegregation). The fraction of solid rapidly increases due to microsegregation (Figure $5 b$ ) but the dendrite arms have not yet coalesced or bridged, even at $\mathrm{fs}=0.82$ (Figure 5c). At much longer times and thus deeper in the mushy zone, the volume fraction of solid has increased only slightly but isolated pockets of liquid now remain in between dendrite arms which have coalesced (Figures 5d-f). This region of the mush can resist and deform plastically when subject to tensile stresses. As pointed by Clyne and Davies [4], the critical region for hot tearing in an alloy corresponds to the zone of Figure $5 \mathrm{c}$ : in this region, the film of interdendritic liquid is continuous and can open easily if thermal stresses are induced and transmitted by the coherent mush located underneath. The only resistance this film can oppose is the pressure of "cavitation", i.e., the pressure at which nucleation of a first void, possibly leading to a crack, will start. On the other hand, any opening of this continuous interdendritic liquid film in this zone can hardly be compensated for by feeding from the upper region of the mush because of the high volume fraction of solid (i.e., low permeability).

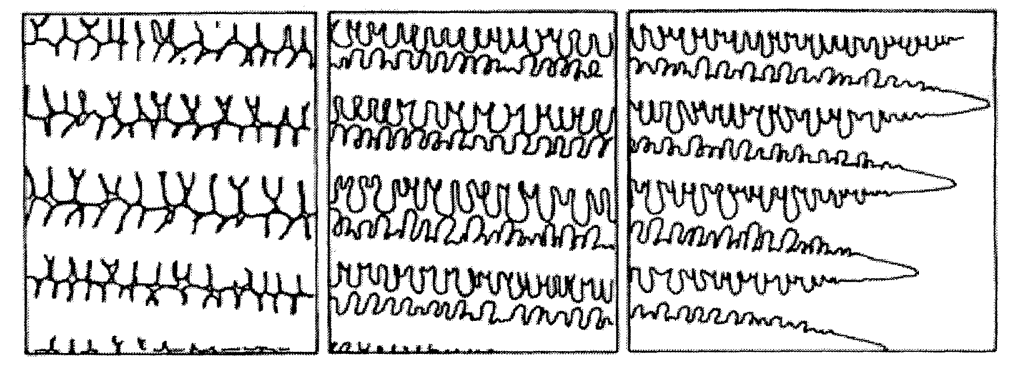
(c) $\mathrm{t}=30 \mathrm{~s}$
(b) $\mathrm{t}=10 \mathrm{~s}$
(a) $\mathrm{t}=0 \mathrm{~s}$

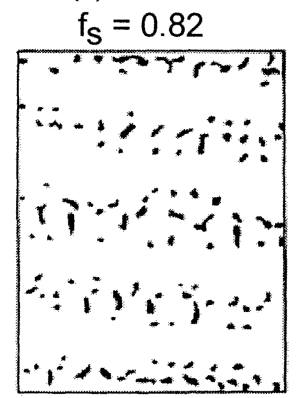

(d) $\mathrm{t}=75 \mathrm{~s}$

$f_{S}=0.94$

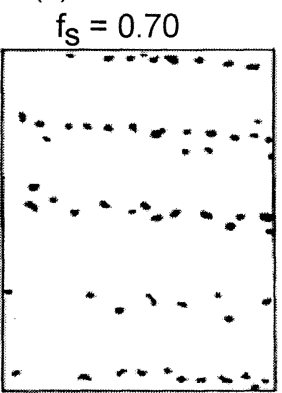

(e) $\mathrm{t}=210 \mathrm{~s}$

$f_{S}=0.97$

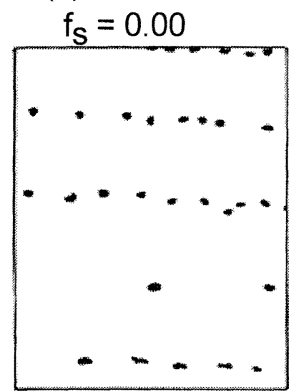

(f) $\mathrm{t}=1500 \mathrm{~s}$

$\mathrm{f}_{\mathrm{S}}=0.98$

Figure 5: microscopy observations of a succinonitrile-acetone alloy which has been directionally solidified in a Bridgman-type apparatus [1]. 


\subsection{Derivation of a new hot tearing criterion}

Details of the derivation of the model can be found in [1] and the main features of the criterion are reported hereafter. Figure 6 is a schematic diagram of the columnar dendritic growth seen in figure 5. In this case, the dendrites are assumed to grow in a given thermal gradient, $\mathrm{G}$, and with a velocity, $v$, equal to the speed of the liquidus isotherm. This velocity points towards the right and therefore, the liquid has to flow from right to left in order to compensate for shrinkage, the specific mass of the solid being larger than that of the liquid for most metallic alloys. If the dendritic network is submitted to a tensile deformation $\varepsilon$ perpendicular to the growth direction, the flow should also compensate for that deformation if no hot tears form. The pressure in the interdendritic liquid is schematically represented at the bottom of Figure 6: it decreases from the metallostatic pressure, $\mathrm{p}_{\mathrm{m}}$, near the dendrite tips. If the pressure falls below a cavitation pressure, $\mathrm{p}_{\mathrm{c}}$, a void may form (black region in Figure 6) and give rise to a crack. In other words, in order to avoid hot tears, liquid feeding is necessary to compensate for the opening of the mush experienced by the roots of the dendrites perpendicularly to the growing direction and induced by the overall thermal stresses in the solidifying part. The criterion is therefore based on the derivation of the two pressure drop contributions associated with deformation and shrinkage respectively. To do so, a mass balance is performed at the scale of a small volume element of the mushy zone in a reference frame attached to the isotherms and under steady state conditions [1].

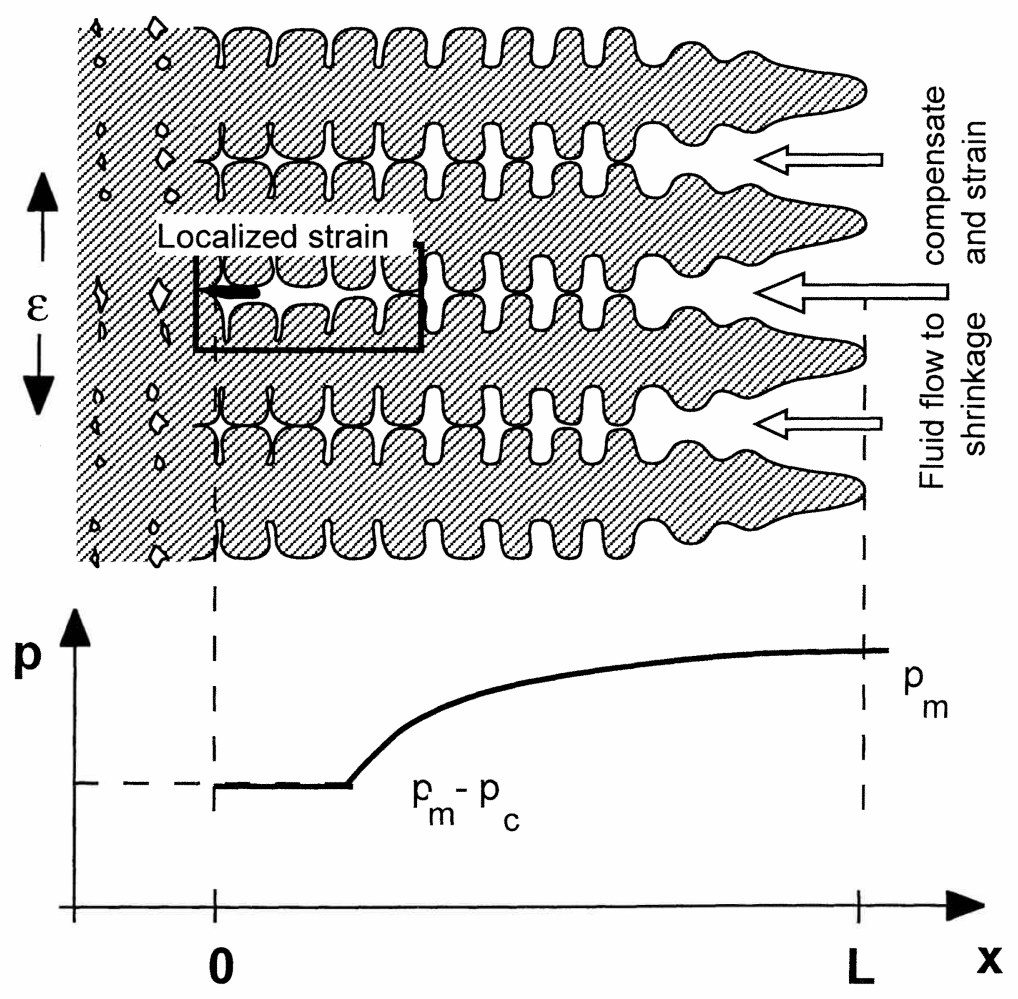

Figure 6: schematics of the formation of a hot tear in between columnar dendrites as a result of a localised strain transmitted by the coherent dendrites below. The pressure drop in the interdendritic liquid is also indicated. 
Under such conditions, it can be shown that the strain rate, $\dot{\varepsilon}_{\mathrm{p}}$, experienced by the mush at the root of the dendrites i.e. near the eutectic temperature, must be such that $[1,15]$ :

$$
\dot{\varepsilon}_{\mathrm{p}}<\dot{\varepsilon}_{\mathrm{p}}^{\max }\left(\lambda_{2}, \mathrm{v}, \Delta \mathrm{P}, \mu, \beta, \mathrm{G}\right)
$$

In this equation, $\dot{\varepsilon}_{\mathrm{p}}{ }^{\max }$ is the maximum plastic strain rate that can be sustained by the mush perpendicularly to the local thermal gradient $\mathrm{G}$. It corresponds to a critical depression $\Delta \mathrm{P}$ at which cracks would nucleate. $\mu$ is the dynamic viscosity $\left(10^{-3}\right.$ Pas $), \lambda_{2}$ is the secondary arm spacing, $v$ the solidification rate and $\beta$ is the shrinkage factor (around $6 \%$ for aluminium alloys) [1].

\section{FEM IMPLEMENTATION OF THE HOT TEARING CRITERION}

In the present case, the secondary dendrite arm spacing was evaluated to $100 \mu \mathrm{m}$ and $\dot{\varepsilon}_{\mathrm{p}}{ }^{\text {max }}$ was calculated assuming solidification under Scheil's conditions. Eventually, referring to the work of Ampuero et al. [17], the critical pressure drop was set to $10^{3} \mathrm{~Pa}$. All these values yield a maximum strain rate $\dot{\varepsilon}_{\mathrm{p}}$ max $=4.10^{-6} \mathrm{~s}^{-1}$ at the eutectic temperature. In figure 7 , the computed hoop and axial strain rate components experienced by the solidifying alloy at the eutectic temperature, $548^{\circ} \mathrm{C}$, are represented as a function of the radius together with the maximum strain rate derived by the hot tearing criterion presented above.

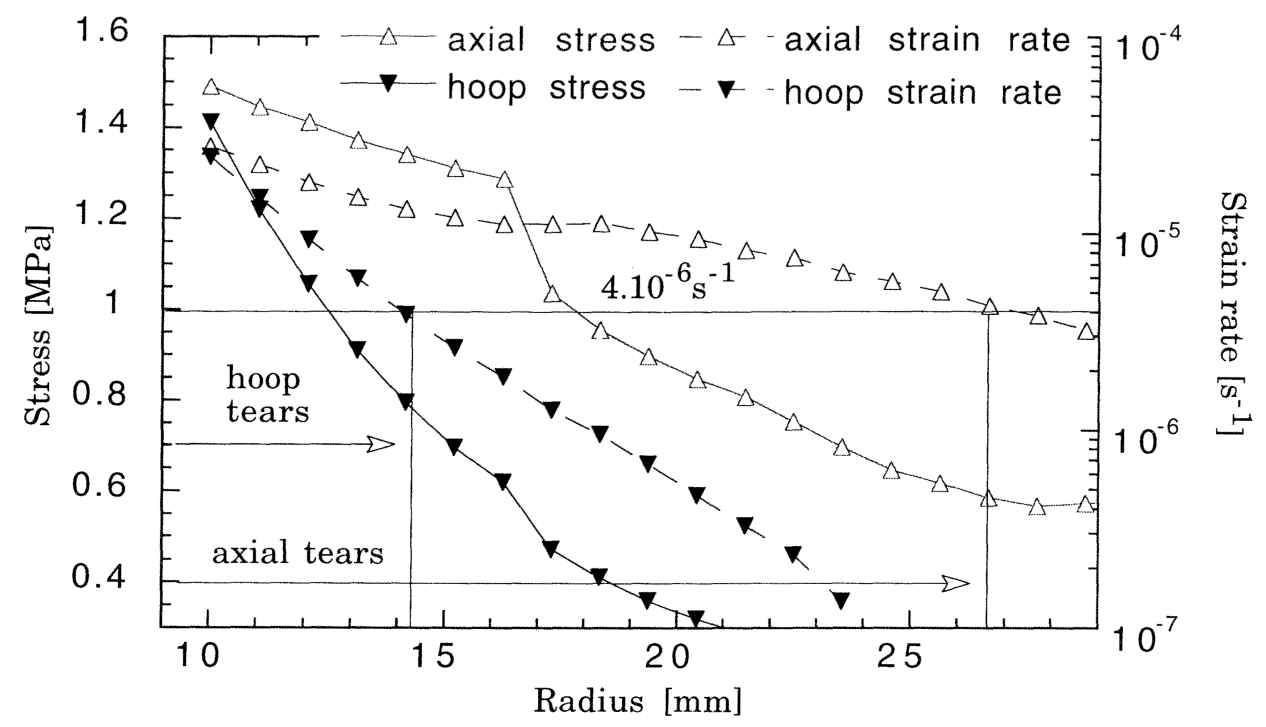

Figure 7: Computed hoop and axial strain rates and stresses at the root of the dendrites, i.e. at Teut, as a function of the radius. Also shown on the graph is the maximum strain rate derived by the hot tearing model.

At the beginning of solidification of the metal around the inner tube, the computed hoop and axial stresses are tensile and the corresponding strain rate components are higher than $\dot{\varepsilon}_{\mathrm{p}}$ max. This means that the thermally induced stresses lead to the initiation and propagation of hot tears. As solidification proceeds, the stress level decreases and the hoop strain rate first, then the axial strain rate, become lower than $\dot{\varepsilon}_{\mathrm{p}}{ }^{\max }$. From this point on, hot tears which were initiated at the beginning of the test would stop propagating according to the criterion. Note that the predicted crack length is lower for hoop tears $(5 \mathrm{~mm})$ than for the axial tears $(15 \mathrm{~mm}$ ), as observed on the macrographs (see fig. 2). Moreover, the stress level in the region where hot tears stop propagating is around $0.8 \mathrm{MPa}$ for hoop tears and 0.6 MPa for axial tears. These 
results are in between the measurements of Wiesniewski [11] who found an average rupture stress of 0.5 MPa for non grain refined $\mathrm{AlCu} 4,5 \%$ tested at a strain rate of $10^{-5} \mathrm{~s}^{-1}$ and at $550^{\circ} \mathrm{C}$, and the recent findings of Suvanchai [12] who measured tensile strength very close to $1 \mathrm{MPa}$ for the non-grain refined $\mathrm{AlCu} 4,5 \%$ alloy near its eutectic temperature.

The new hot tearing criterion was also implemented in the computation model of the ring mould test. A hot tearing index, called hti, was defined as follows:

$$
\begin{aligned}
& \text { if } \dot{\varepsilon}_{\mathrm{p}} \text { (Teut) }<\dot{\varepsilon}_{\mathrm{p}} \max \left(\lambda_{2}, \mathrm{v}, \Delta \mathrm{P}, \mu, \beta, \mathrm{G}\right), \text { hti }=0 \\
& \text { if } \dot{\varepsilon}_{\mathrm{p}} \text { (Teut) } \geq \dot{\varepsilon}_{\mathrm{p}}{ }^{\max }\left(\lambda_{2}, \mathrm{v}, \Delta \mathrm{P}, \mu, \beta, \mathrm{G}\right), \text { hti }=1
\end{aligned}
$$

where $\dot{\varepsilon}_{\mathrm{p}}$ (Teut) is the Von Mises equivalent strain rate computed at the integration point of each element and at the eutectic temperature. A value of 1 for the hti means that hot tears are initiated locally whereas a value of 0 is affected to safe regions. The hot tearing index was included in the thermomechanical model of the test with the help of a solution dependent variable [18]. Figure 8 shows the computed distribution of the hot tearing index after the whole part has cooled down. The region where the index has a value of 1, i.e. where initiation of hot tears are predicted by the criterion, is situated on the inner tube as observed experimentally in figure 2. This zone is a cylinder, approximately $20 \mathrm{~mm}$ in radius. The radius of the inner core being 10 $\mathrm{mm}$, the predicted crack length is about $10 \mathrm{~mm}$. This value is in between the predicted lengths of the hoop tears, $5 \mathrm{~mm}$, and of the axial tears, $15 \mathrm{~mm}$ (see figure 7). This is not surprising since the equivalent strain rate was considered for the computation of the index, and not the tangential and axial components of the strain rate as in figure 6 . Nevertheless, this strategy seems promising in order to determine locations that are most sensitive to hot tears.

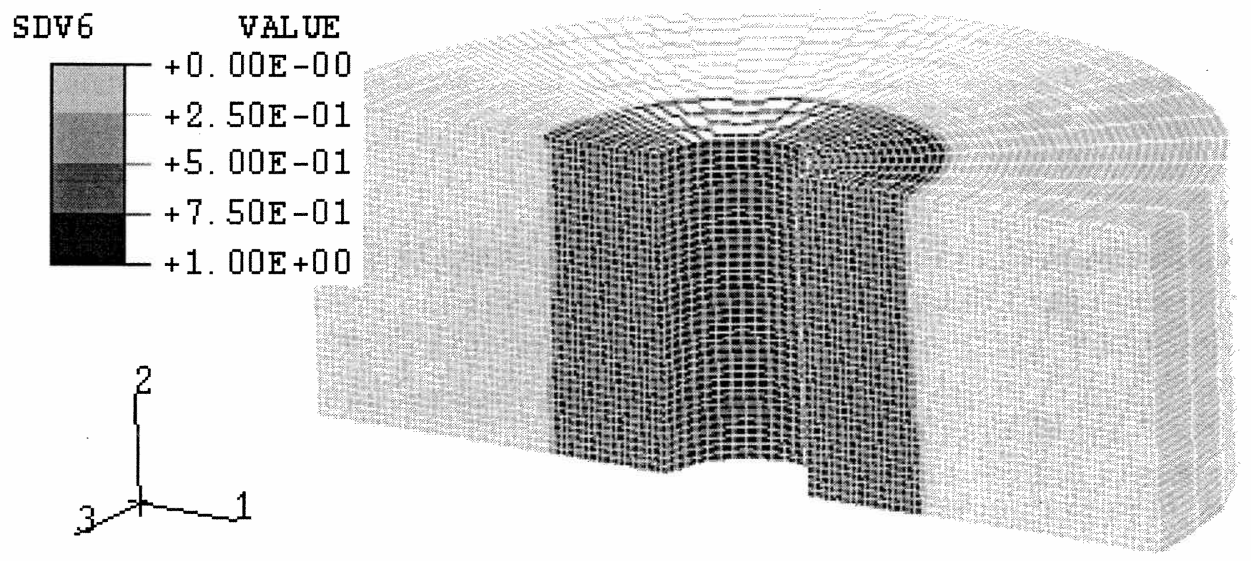

Figure 8: Contour of the computed hot tearing index based on the equivalent strain rate computed at the root of the dendrites, i.e. at Teut. 


\section{CONCLUSION}

- A hot tearing criterion derived for columnar microstructure [1] and based upon the ability of the interdendritic liquid flow to compensate for the thermally induced mechanical deformation of the roots of the dendrites, i.e. at temperatures close to the eutectic temperature, has been applied on ring mould tests of non-grain refined aluminium copper alloy. During the early stage of solidification of the alloy against the inner tube, the hoop and axial strain rates are higher than the maximum strain rate predicted by the hot tearing criterion thus leading to the initiation of interdendritic hot tears. The predicted crack length correspond to the point where the strain rate becomes lower than the maximum strain rate owing to the decrease of the stress level.

- The criterion presented here is only an indicator of the appearance (or initiation), and not of the propagation, of hot tears. Further refinements of the model should be envisaged such as more complex cooling conditions, accounting of gas segregation, equiaxed instead of columnar structures, etc. The model for the first appearance (initiation) of a hot tear is also rather crude: it corresponds to instantaneous nucleation at a critical depression. More sophisticated models in which the time would appear (i.e., nucleation rate) could also be used to predict hot tear formation. The model was intentionally made simple so that the mechanisms clearly appear.

- When extended to equiaxed dendritic or globular microstructures, the present hot tearing criterion could be implemented in thermomechanical models of casting such as the direct chill semi-continuous casting process, so as to predict the occurrence of hot tearing and improve the process.

\section{References}

[1] M. Rappaz, J.M. Drezet and M. Gremaud: A New Hot Tearing Criterion, to appear in Metallurgical and Materials Transactions.

[2] J. Campbell, Castings (Butterworth-Heinemann, Oxford, 1991).

[3] F. Decultieux, Ph. D. Thesis, E. N. S. Mines de Paris (1996).

[4] T. W. Clyne and G. J. Davies, Brit. Found. 74 (1981) 65.

[5] D. Warrington and D. G. McCartney, Cast Metals 2 (1989) 134.

[6] M. Rappaz: Hot tearing and stress-related defects, in Advanced Course in Solidification, in Villars, Switzerland, Calcom SA, 1996.

[7] U. Feurer, Giesserei Forsch. 2 (1976) 75.

[8] Y. F. Guven and J. D. Hunt, Cast Metals 1 (1988) 104.

[9] P. Ackermann, W. Kurz and Heinemann, Mater. Sc. Engng. 75 (1985) 79.

[10] P. Vicente, Ph. D. Thesis, E. N. S. Mines de Paris (1994).

[11] Wisniewski P. and H. D. Brody in MCWASP V, TMS, 1991, p. 273.

[12] P. Suvanchai, T. Okane and T. Umeda, Solidification Processing Conference, July 1997, edited by J. Beech and H. Jones. p. 190.

[13] M. Rappaz, J.-L. Desbiolles, J. M. Drezet, Ch.-A. Gandin, A. Jacot and Ph. Thévoz in MCWASP VII, TMS, 1995, p. 449.

[14] J.M. Drezet and M. Rappaz in Met. Trans. 27A, no. 10, October 1996, pp. 3214-3225.

[15] M. Bellet, F. Decultieux, M. Menai, F. Bay, C. Levaillant, J.L. Chenao, P. Schmidt and I.L. Svensson in Met. Trans. 27B, February 1996, pp. 81-99.

[16] J.M. Drezet and M. Rappaz: A new hot tearing criterion for aluminium alloys, first EsaForm conference on material forming, Sophia Antipolis, France, March 1998.

[17] J. Ampuero, A. F. A. Hoadley and M. Rappaz in MCWASP V, TMS, 1991, p.449.

[18] Abaqus theory manual, version 5.7, K. Hibbit and J. Sorensen, Hibbit, Karlson and Sorensen, Inc., Providence, 1998. 